\title{
Status of Post Irradiation Examination of FCAB and FCAT Irradiation Capsules
}

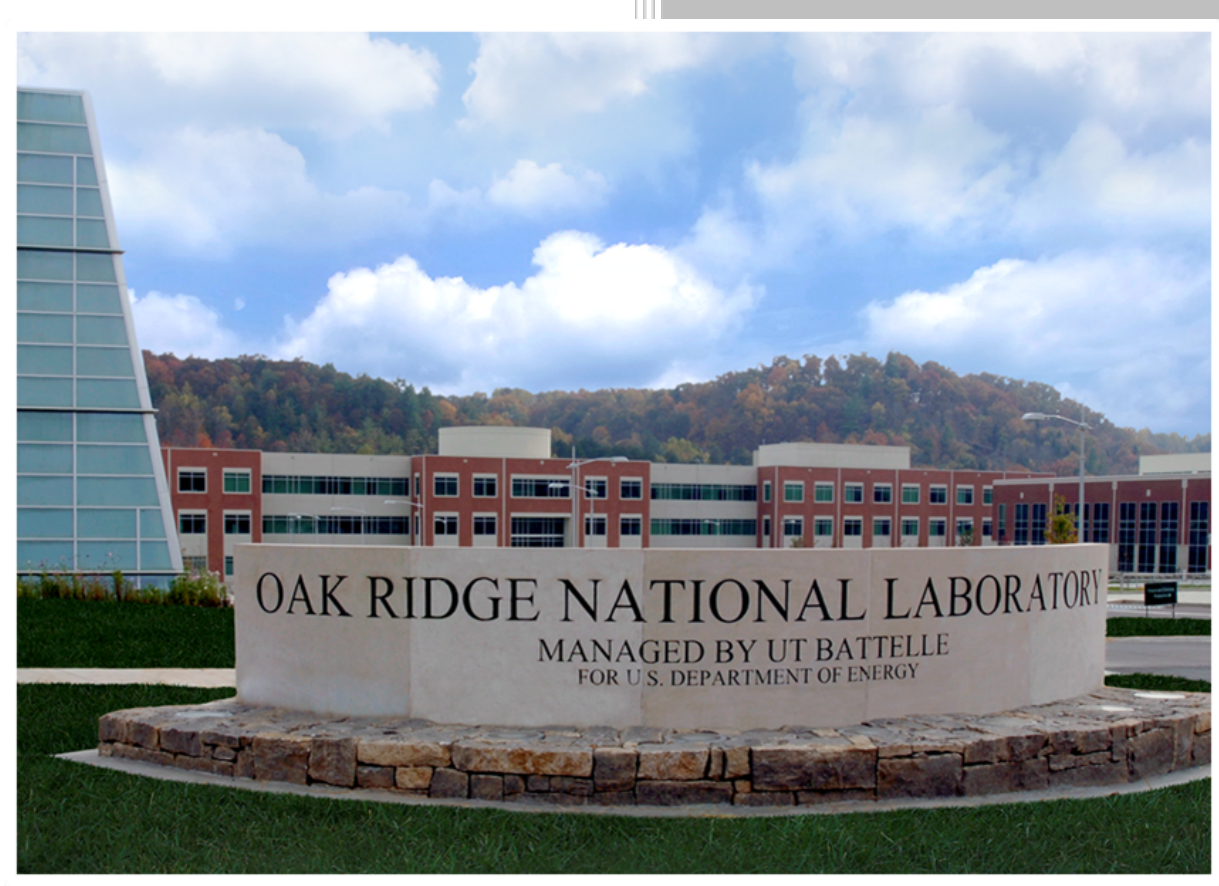

Kevin G. Field

Yukinori Yamamoto

Richard H. Howard

September $29^{\text {th }}, 2016$ 


\section{DOCUMENT AVAILABILITY}

Reports produced after January 1, 1996, are generally available free via US Department of Energy (DOE) SciTech Connect.

Website http://www.osti.gov/scitech/

Reports produced before January 1, 1996, may be purchased by members of the public from the following source:

National Technical Information Service

5285 Port Royal Road

Springfield, VA 22161

Telephone 703-605-6000 (1-800-553-6847)

TDD 703-487-4639

Fax 703-605-6900

E-mail info@ntis.gov

Website http://www.ntis.gov/help/ordermethods.aspx

Reports are available to DOE employees, DOE contractors, Energy Technology Data Exchange representatives, and International Nuclear Information System representatives from the following source:

Office of Scientific and Technical Information

PO Box 62

Oak Ridge, TN 37831

Telephone 865-576-8401

Fax 865-576-5728

E-mail reports@osti.gov

Website http://www.osti.gov/contact.html

This report was prepared as an account of work sponsored by an agency of the United States Government. Neither the United States Government nor any agency thereof, nor any of their employees, makes any warranty, express or implied, or assumes any legal liability or responsibility for the accuracy, completeness, or usefulness of any information, apparatus, product, or process disclosed, or represents that its use would not infringe privately owned rights. Reference herein to any specific commercial product, process, or service by trade name, trademark, manufacturer, or otherwise, does not necessarily constitute or imply its endorsement, recommendation, or favoring by the United States Government or any agency thereof. The views and opinions of authors expressed herein do not necessarily state or reflect those of the United States Government or any agency thereof. 
Fuel Cycle Research and Development (FCRD)

\section{Status of Post Irradiation Examination of FCAB and FCAT Irradiation Capsules}

Kevin G. Field

Yukinori Yamamoto

Richard H. Howard

Date Published: September 29 ${ }^{\text {th }}, 2016$

Milestone Number: M3FT-16OR020203053

Prepared by

OAK RIDGE NATIONAL LABORATORY

Oak Ridge, TN 37831-6283

managed by

UT-BATTELLE, LLC

for the

US DEPARTMENT OF ENERGY

under contract DE-AC05-00OR22725 



\section{CONTENTS}

Page

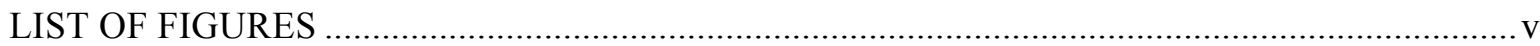

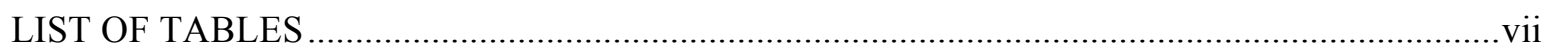

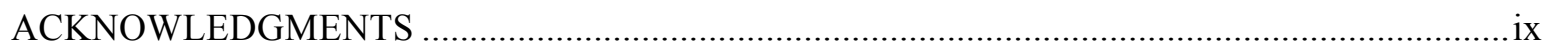

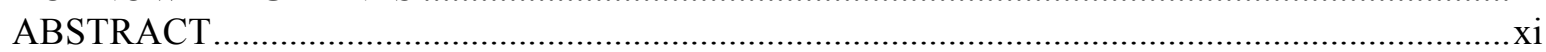

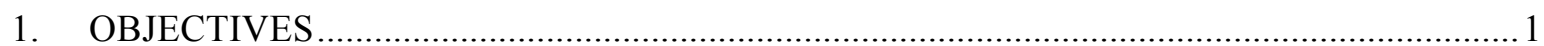

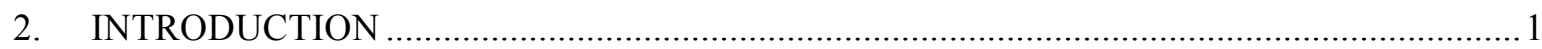

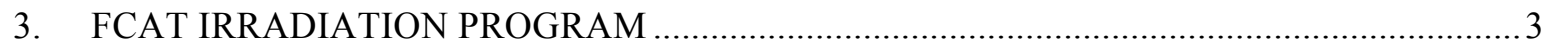

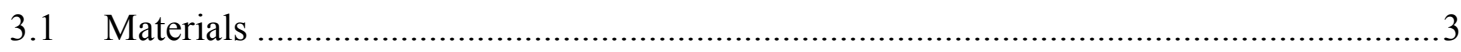

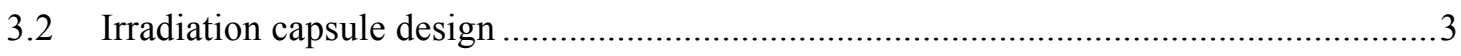

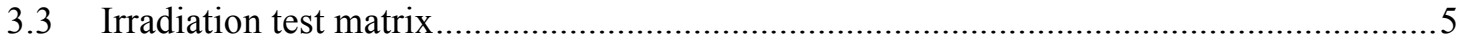

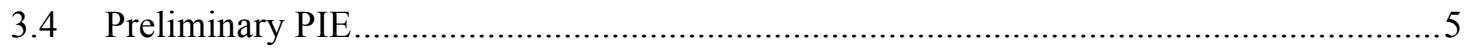

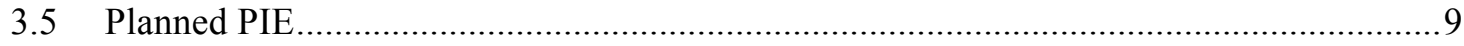

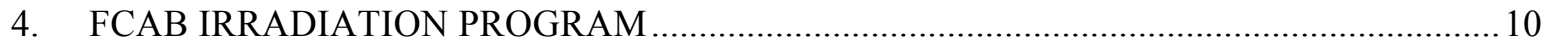

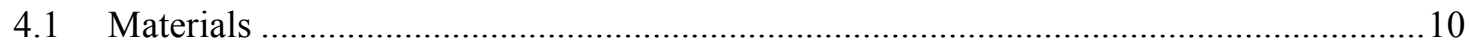

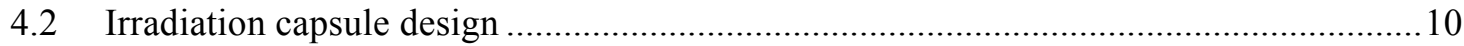

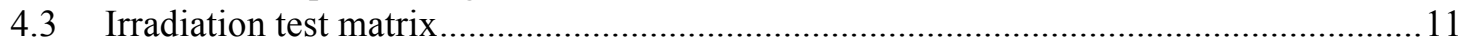

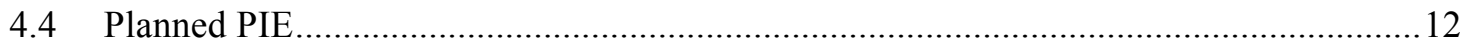

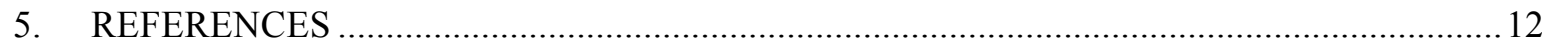





\section{LIST OF FIGURES}

Figure 1: Finalized HFIR rabbit design for the tensile bar specimens. ........................................ 4

Figure 2: Predicted temperature contours for a $330^{\circ} \mathrm{C}$ irradiation in HFIR: a) specimen temperature contours and b) SiC thermometry contours. All temperatures in ${ }^{\circ} \mathrm{C}$. ............................5

Figure 3: Plots showing engineering stress-strain curves before and after neutron irradiation to 1.8$1.9 \mathrm{dpa}$ between $194.5^{\circ} \mathrm{C}$ and $565.5^{\circ} \mathrm{C}$ when tested at room temperature $\left(\mathrm{T}_{\text {test }}=24^{\circ} \mathrm{C}\right) \ldots 9$

Figure 4: Finalized HFIR rabbit design for the bend bar specimens. 10

Figure 5: Predicted temperature contours for a $330^{\circ} \mathrm{C}$ irradiation in HFIR: a) specimen temperature contours and b) $\mathrm{SiC}$ thermometry contours. All temperatures in ${ }^{\circ} \mathrm{C}$.

Figure 6: Sample loading scheme for each FCAB irradiation capsule. ID numbers in the yellow rectangles represent ID numbers for individual 4 notch bend bar specimens. ID numbers in white area cut-outs represent individual passive SiC thermometry. 



\section{LIST OF TABLES}

Table 1: Candidate FeCrAl alloys in weight percentage ...............................................................

Table 2: Summary of FCAT capsule irradiation conditions....................................................... 5

Table 3: Condition of SiC thermometry samples originating from FCAT low dose irradiation

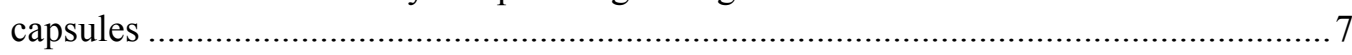

Table 4: Results of dilatometric analysis of $\mathrm{SiC}$ thermometry bars contained within irradiated

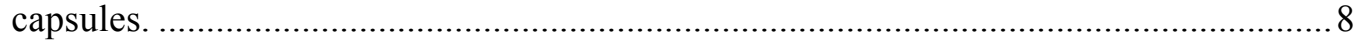

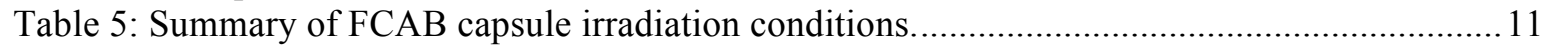





\section{ACKNOWLEDGMENTS}

Research was sponsored by the DOE's Office of Nuclear Energy, Advanced Fuel Campaign of the Fuel Cycle R\&D Program. Neutron irradiation of at ORNL's HFIR user facility was sponsored by the Scientific User Facilities Division, Office of Basic Energy Sciences, DOE. This report was authored by UT-Battelle LLC under Contract No. DE-AC05-00OR22725 with the US Department of Energy. 



\begin{abstract}
A series of irradiation programs are ongoing to address the need for determining the radiation tolerance of $\mathrm{FeCrAl}$ alloys. These irradiation programs, deemed the FCAT and FCAB irradiation programs, use the High Flux Isotope Reactor (HFIR) to irradiate second generation wrought FeCrAl alloys and early generation powder-metallurgy (PM) oxide dispersion strengthened (ODS) FeCrAl alloys. Irradiations have been or are being performed at temperatures of $200^{\circ} \mathrm{C}, 330^{\circ} \mathrm{C}$, and $550^{\circ} \mathrm{C}$ from doses of $1.8 \mathrm{dpa}$ up to $16 \mathrm{dpa}$. Preliminary post-irradiation examination (PIE) on low dose $(<2 \mathrm{dpa})$ irradiation capsules of tensile specimens has been performed. Analysis of co-irradiated $\mathrm{SiC}$ thermometry have shown reasonable matching between the nominal irradiation temperatures and the target irradiation temperatures. Room temperature tensile tests have shown typical radiation-induced hardening and embrittlement at irradiations of $200^{\circ} \mathrm{C}$ and $330^{\circ} \mathrm{C}$ but a propensity for softening when irradiated to $550^{\circ} \mathrm{C}$ for the wrought alloys. The PM-ODS FeCrAl specimens showed less hardening compared to the wrought alloys. Future PIE includes high temperature tensile tests on the low dose irradiation capsules as well as the determination of reference fracture toughness transition temperature, $\mathrm{T}_{\mathrm{o}}$, in alloys irradiated to $7 \mathrm{dpa}$ and higher.
\end{abstract}





\section{OBJECTIVES}

The objectives of the FeCrAl-Tensile (FCAT) and FeCrAl-Bend Bar (FCAB) irradiation programs are to provide critical data on the radiation-induced microstructural changes and the resulting change in mechanical properties of candidate $\mathrm{FeCrAl}$ alloys for accident tolerant fuel (ATF) cladding applications. Key variables include the changes in microstructural and mechanical properties with radiation dose (dpa), temperature, and alloy composition. Data derived from mechanical and microstructural evaluations will be used to assist in the development of structure-property relationships which can then be applied during alloy development efforts for ATF FeCrAl alloys.

\section{INTRODUCTION}

Recent years have seen an increased interest in novel fuel-clad systems that exhibit high temperature oxidation resistance as a means to increase the accident tolerance of commercial light water reactors (LWRs). Several different technologies are under development such as SiC$\mathrm{SiC}$ composite cladding and $\mathrm{FeCrAl}$ alloy cladding. A key component towards the development of these fuel-clad systems is the determination of their performance during normal operation. One key factor during normal operation is the radiation tolerance of the candidate systems. In particular, changes in the mechanical performance such as radiation-induced hardening and embrittlement are of special interest.

Preliminary investigations into the radiation tolerance of four model $\mathrm{FeCrAl}$ alloys (Fe-10Cr4.8Al, Fe-12Cr-4.4Al, Fe-15Cr-3.9Al, and Fe-18Cr-2.9Al) irradiated to 1.8 dpa at $382^{\circ} \mathrm{C}$ have shown the susceptibility of $\mathrm{FeCrAl}$ alloys to radiation-induced hardening and embrittlement [1]. This is primarily due to their similar response to $\mathrm{FeCr}$ alloys where radiation induces microstructures with Cr-rich $\alpha^{\prime}$ precipitates, black dots, line dislocations, and $a / 2\langle 111\rangle$ and $a\langle 100\rangle$ dislocation loops at typical LWR temperatures. The degree of radiation-induced hardening and embrittlement was linked to $\mathrm{Cr}$ content of the model $\mathrm{FeCrAl}$ alloys investigated. Increasing the $\mathrm{Cr}$ content resulted in an increased precipitation of the Cr-rich $\alpha^{\prime}$ phase which, at significant number densities, greatly increased the yield strength and led to a loss of ductility. The Cr-rich $\alpha^{\prime}$ phase, although not studied in the previously mentioned research on FeCrAl alloys, has also been linked to changes in the fracture properties of $\mathrm{FeCr}$ alloys including shifts in either the reference fracture toughness transition temperature $\left(\mathrm{T}_{\mathrm{o}}\right)$ and/or the ductile-to-brittle transition temperature (DBTT). These shifts in $\mathrm{T}_{\mathrm{o}}$ and DBTT have been linked to the change in yield strength for neutron irradiated commercial reduced activation ferritic/martensitic (RAFM) steels [2].

Currently, no empirically determined correlation between the microstructure, tensile properties, and fracture properties exists for the candidate $\mathrm{FeCrAl}$ cladding system. Even further, no detailed study has been conducted to determine the influence of irradiation dose, temperature, and/or alloy composition on any possible correlations within the $\mathrm{FeCrAl}$ alloy class. Recently, a series of irradiation programs have been developed to fill this knowledge gap and begin establishing the effects of radiation on the hardening and embrittlement of FeCrAl alloys between the irradiation temperatures of $200-600^{\circ} \mathrm{C}$ and radiation damage doses up to $16 \mathrm{dpa}$. 
The irradiation programs of interests are the FeCrAl-Tensile (FCAT) and FeCrAl-Bend Bar (FCAB) irradiation programs [3]. These programs use the central flux trap of the High Flux Isotope Reactor (HFIR) and small (less than 3 inches long) irradiation capsules to perform accelerated neutron irradiation materials screening on candidate FeCrAl alloys. Unfortunately, a single specimen cannot accurately test both the tensile and fracture properties of an irradiated alloy. Three different sub-sized or miniature test specimens are used within these programs due to the limited volume of the irradiation capsules and the need for different geometries to test different material properties. The three different miniature test specimens are, M4-PCVVN bend bar specimens for fracture toughness, SS-J2 sub-sized tensile specimens for tensile testing, and, under the NEET program, an experimental configuration designated as the SS-2E ultra-miniature tensile specimen. The M4-PCVVN and SS-J2 tensile specimens have seen extensive use in irradiation campaigns within the HFIR as well as other materials test reactors and hence a rich database for these specimen geometries has been collected for varying materials and irradiation conditions. The SS-2E configuration is a novel design aimed at significantly reducing the volume of a tensile specimen to allow for rapid assessment of mechanical properties post-irradiation without the need for extensive radiological shielding facilities such as a standard hot-cell facility $[4]$.

The limited volume in each irradiation capsule prevents the irradiation of all three geometries in a single irradiation capsule for multiple alloys at a single irradiation condition. Hence, the need for two irradiation programs. The primary program, FCAT, was designed to irradiate both the SS-J2 and SS-2E tensile specimens and covers a larger dose (dpa) range. The FCAB program irradiates solely the M4-PCVVN bend bar geometry and serves as compliment capsules to the higher dose FCAT capsules. The FCAT design can accommodate a wider variety of alloys within a single capsule while the FCAB design can only hold 4 bend bar specimens, typically meaning only two alloys per capsule. The goal is to provide samples out of the FCAB and FCAT programs with nearly identical irradiation conditions including radiation dose and temperature as well as power history and other variables that might influence changes in the microstructure or mechanical properties.

As noted, both the contributions of irradiation dose and temperature are being studied in both the FCAT and FCAB irradiation programs. Hence, three different target temperatures were selected: $200^{\circ} \mathrm{C}, 330^{\circ} \mathrm{C}$, and $550^{\circ} \mathrm{C}$. The temperatures were selected to place the irradiated alloys in three unique regimes: a dislocation loop dominated regime, a mixed dislocation loop and precipitation dominated regime, and softening or limited dislocation loop dominated regime, respectively. By placing the alloys in different regimes, the assessment of microstructural variation on radiationinduced hardening and embrittlement can be completed. Furthermore, three separate target doses were selected: $2 \mathrm{dpa}, 8 \mathrm{dpa}$, and $16 \mathrm{dpa}$. These target doses correspond to those studied previously for model $\mathrm{FeCrAl}$ alloys $[3,16]$ allowing for direct assessment on the difference in the radiation tolerance between model and engineered FeCrAl alloys. Due to the splitting of the two irradiation capsule configurations, it was determined that the 2 dpa FCAB irradiation capsules would not be fielded in the HFIR. This decision is based on prior knowledge that the alloys of interest might not reach saturation in the fracture toughness shift and hence would not provide the needed data to meet the objectives of the irradiation campaign. 
The following report summarizes the FCAT and FCAB irradiation program including the currently determined irradiation conditions as well as provides insight into the preliminary postirradiation examination (PIE) completed on specimens derived from these programs.

\section{FCAT IRRADIATION PROGRAM}

\subsection{Materials}

The FCAY irradiation program [5] was focused on studying a wide-range of model FeCrAl alloys with varying amounts of $\mathrm{Cr}$ and $\mathrm{Al}$ additions. Unfortunately, the FCAY program did not have compositions that systematically varied these alloying additions making conclusions on the role of $\mathrm{Cr}$ and/or $\mathrm{Al}$ on the radiation tolerance of $\mathrm{FeCrAl}$ alloys inherently difficult. The FCAT irradiation program seeks to remedy this issue by performing studies on a series of engineering grade $\mathrm{FeCrAl}$ alloys.

The primary alloys for the FCAT irradiation program are based on a $13 \mathrm{wt} . \% \mathrm{Cr}$ base content with 2 wt. $\%$ Mo, 0.2 wt. $\% \mathrm{Si}$, and 0.05 wt.\% Y in an Fe matrix. The Al content is allowed to vary from 5 to $7 \mathrm{wt} . \%$. Additionally, a lower Cr variant (10 wt.\%) with 6 wt.\% Al and similar minor alloying variants is also included. An oxide dispersion strengthened (ODS) variant derived from powder metallurgy techniques is included to study the effect of high-sink strength and the stability of the nano-cluster oxides on the radiation tolerance of FeCrAl. Finally, several other prototype $\mathrm{FeCrAl}$ alloys fabricated under the NEET Reactor Materials program are added to the test matrix, but will not be discussed here. The resulting base materials means three distinct alloy classes: FeCrAl alloys with varying-Al additions, $\mathrm{FeCrAl}$ alloys with varying-Cr additions, and FeCrAl alloys with oxide dispersions. A summary of the alloys is provided in Table 1. Details on the processing routes, as-received microstructural characterization, and mechanical properties information for the alloys can be found in previous reports [5-7].

Table 1: Candidate FeCrAl alloys in weight percentage

\begin{tabular}{|c|c|c|c|c|c|c|c|c|c|c|c|}
\hline \multirow{2}{*}{ Alloy } & \multicolumn{11}{|c|}{ Composition (wt \%) } \\
\hline & $\mathbf{F e}$ & $\mathrm{Cr}$ & Al & $\mathbf{Y}$ & $\mathrm{C}$ & $\mathbf{S}$ & $\mathbf{O}$ & $\mathbf{N}$ & $\mathbf{P}$ & Si & Mo \\
\hline C06M & 81.80 & 10.03 & 6.00 & 0.010 & 0.003 & 0.0012 & 0.0016 & 0.0004 & 0.003 & 0.180 & 1.96 \\
\hline C35M & 79.43 & 13.06 & 5.31 & 0.053 & 0.001 & $<0.0003$ & 0.0012 & 0.0003 & 0.007 & 0.130 & 2.00 \\
\hline C36M & 78.8 & 12.98 & 6.00 & 0.040 & 0.003 & $<0.0003$ & 0.0016 & 0.0002 & $<0.002$ & 0.180 & 1.98 \\
\hline C37M & 77.49 & 13.01 & 7.22 & 0.081 & 0.001 & $<0.0003$ & 0.0026 & 0.0002 & 0.004 & 0.190 & 1.99 \\
\hline $125 \mathrm{YF}$ & 82.99 & 11.67 & 4.73 & 0.19 & 0.020 & 0.0030 & 0.192 & 0.0202 & NR & 0.010 & 0.01 \\
\hline
\end{tabular}

\subsection{Irradiation capsule design}

Details on the full irradiation capsule design have been reported previously [3] and will only be discussed briefly. The capsules are designed to hold both SS-J2 type tensile specimens and the newly developed SS-2E type tensile specimens. The design is optimized as a drop-in irradiation capsule for use in the High Flux Isotope Reactor (HFIR) at Oak Ridge National Laboratory (ORNL). At least two alloys per specimen type are fielded in each irradiation capsule. Multiple 
samples are necessary for either repeatability tests and/or room temperature and irradiation temperature tensile tests. As the capsules are drop-in capsules, no active monitoring of the capsule temperatures is provided. Irradiation temperatures are verified using passive $\mathrm{SiC}$ thermometry. Proper dilatometric examination of the $\mathrm{SiC}$ specimens provide details on the general irradiation temperature.

Three separate capsule designs were developed to accommodate the three target temperatures described in the following section. Primary differences between the three designs included changing the radial gas gap between the sub-assembly and outer housing of the irradiation capsule and the outer housing material. Helium gas was used as the fill gas for all three designs. A schematic of the capsule design is provided in Figure 1. Capsule outer housing material varied depending on nominal target irradiation temperature. Lower irradiation temperatures (typically $<450^{\circ} \mathrm{C}$ ) used Al 6061-T6 while higher irradiation temperature capsules used Mo-based alloys.

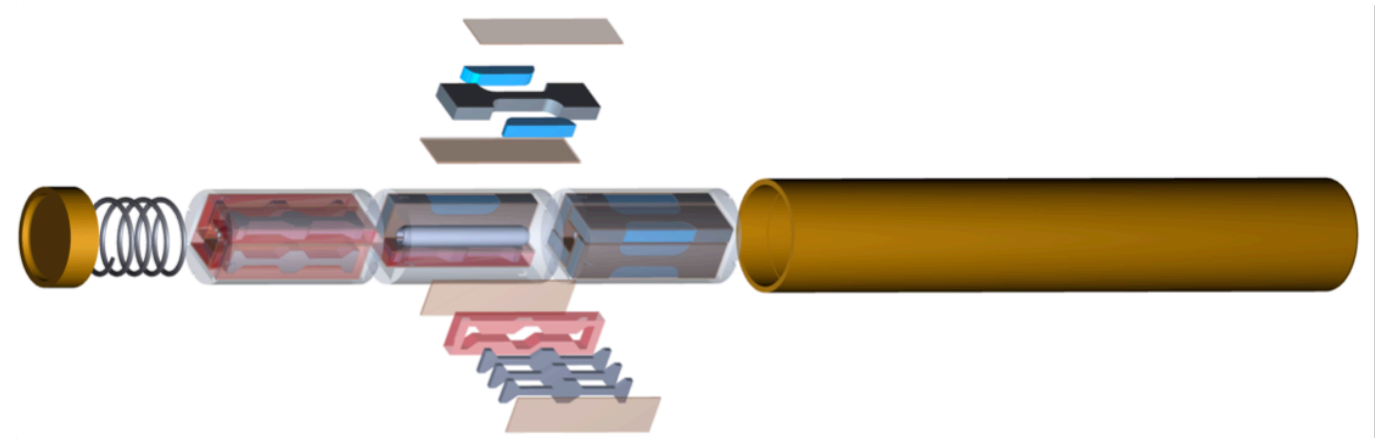

Figure 1: Finalized HFIR irradiation capsule design for the tensile bar specimens.

Determination of the radial gas gap which controls the capsule irradiation temperature was determined by calculations using an ANSYS finite element analysis (FEA) software design. Geometries, and hence thermal gradients, were determined in three dimensions. Standard assumptions for typical HFIR irradiation capsule designs were assumed. The capsules were designed to maintain a total specimen average temperature close to the target irradiation temperatures. An example of the specimen temperatures and thermal gradients for one module of SS-J2 specimens shown Figure 1 is provided in Figure 2a. Figure 2a shows SS-J2 specimens orientated towards the capsule center tend to have higher irradiation temperatures than those near the capsule outer holder and the gage regions tend to have higher general temperatures than regions of the tensile head. Hence, some variation in the microstructure and mechanical properties along the length of a single tensile specimen and from specimen to specimen in the same stack is expected. Figure $2 b$ shows the temperature contours for the passive $\mathrm{SiC}$ thermometry which are in direct contact with the inner SS-J2 specimens in a single module. Note, the SiC bulk temperatures are markedly higher than the specimens as this is expected due to their location within the capsule. Hence, reported temperatures from SiC thermometry will, in general, report slightly higher temperatures than those expected for the bulk average specimen temperatures of a single capsule. 
a)

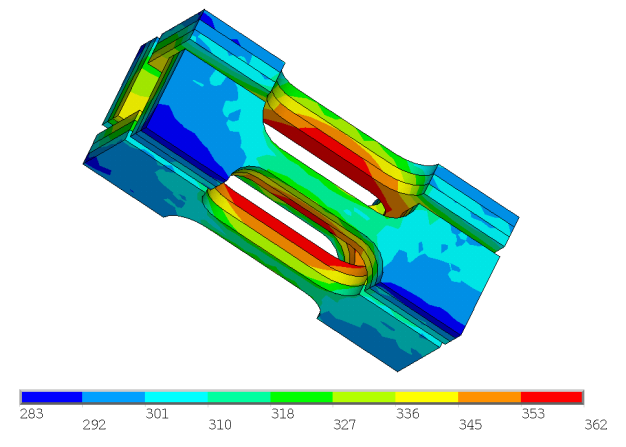

b)

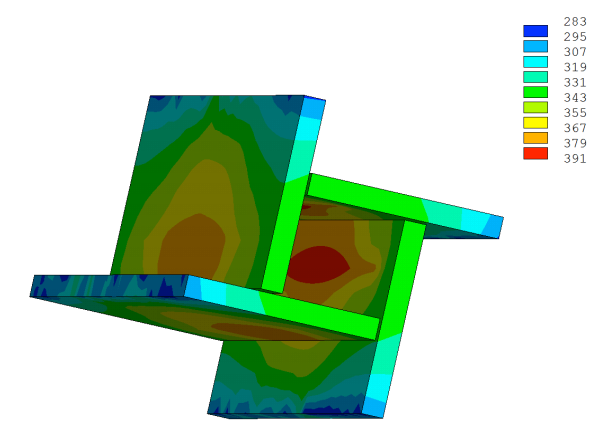

Figure 2: Predicted temperature contours for a $330^{\circ} \mathrm{C}$ irradiation in HFIR: a) specimen temperature contours and b) $\mathrm{SiC}$ thermometry contours. All temperatures in ${ }^{\circ} \mathrm{C}$.

\subsection{Irradiation test matrix}

The objective of the FCAT irradiations were to investigate the contributions of composition, microstructure, irradiation dose, and irradiation temperature on the radiation tolerance of wrought and ODS FeCrAl alloys. Irradiation doses and temperatures were selected to complement the FCAB irradiation program discussed later in this report while providing crossreferencing capabilities to the prior FCAY irradiation program on model FeCrAl alloys. Hence, 3 damage doses at $2 \mathrm{dpa}, 8 \mathrm{dpa}$, and $16 \mathrm{dpa}$ will be investigated each at an irradiation temperature of $200^{\circ} \mathrm{C}, 330^{\circ} \mathrm{C}$, and $550^{\circ} \mathrm{C}$ for a total of nine unique irradiation conditions. Nine separate irradiation capsules are fielded in order to fulfil the test matrix. A summary of the irradiation capsules and the irradiation test matrix for the FCAT irradiation program is provided in in Table 2. Irradiation temperatures are reported as the nominal irradiation temperature determined using $\mathrm{SiC}$ thermometry samples when available.

Table 2: Summary of FCAT capsule irradiation conditions.

\begin{tabular}{|c|c|c|c|c|c|c|}
\hline Capsule ID & $\begin{array}{l}\text { Exposure } \\
\text { Time } \\
\text { (hrs) }\end{array}$ & $\begin{array}{c}\text { Neutron Flux } \\
\left(\mathrm{n} / \mathrm{cm}^{2} \mathrm{~s}\right) \\
\mathrm{E}>0.1 \mathrm{MeV}\end{array}$ & $\begin{array}{c}\text { Neutron Fluence } \\
\left(\mathbf{n} / \mathrm{cm}^{2}\right) \\
\mathrm{E}>0.1 \mathrm{MeV}\end{array}$ & $\begin{array}{c}\text { Dose Rate } \\
\text { (dpa/s) }\end{array}$ & $\begin{array}{l}\text { Dose } \\
\text { (dpa) }\end{array}$ & $\begin{array}{c}\text { Irradiation } \\
\text { Temperature } \\
\left({ }^{\circ} \mathrm{C}\right)\end{array}$ \\
\hline FCAT-01 & 548 & $1.10 \times 10^{15}$ & $2.17 \times 10^{21}$ & $9.8 \times 10^{-7}$ & 1.9 & $194.5 \pm 37.9$ \\
\hline FCAT-02 & 548 & $1.04 \times 10^{15}$ & $2.05 \times 10^{21}$ & $9.3 \times 10^{-7}$ & 1.8 & $363.6 \pm 23.1$ \\
\hline FCAT-03 & 548 & $1.10 \times 10^{15}$ & $2.17 \times 10^{21}$ & $9.8 \times 10^{-7}$ & 1.9 & $559.4 \pm 28.1$ \\
\hline FCAT-04 & $2304 *$ & $1.10 \times 10^{15}$ & $9.12 \times 10^{21} *$ & $9.8 \times 10^{-7} *$ & $8.2 *$ & $200^{*}$ \\
\hline FCAT-05 & $2304 *$ & $1.04 \times 10^{15}$ & $8.62 \times 10^{21 *}$ & $9.3 \times 10^{-7} *$ & $7.7 *$ & $330^{*}$ \\
\hline FCAT-06 & $2304 *$ & $1.10 \times 10^{15}$ & $9.12 \times 10^{21} *$ & $9.8 \times 10^{-7} *$ & $8.2 *$ & $550^{*}$ \\
\hline FCAT-07 & $4608 *$ & $1.10 \times 10^{15}$ & $1.82 \times 10^{22 *}$ & $9.8 \times 10^{-7} *$ & $16.3^{*}$ & $200^{*}$ \\
\hline FCAT-08 & $4608 *$ & $1.04 \times 10^{15}$ & $1.73 \times 10^{22 *}$ & $9.3 \times 10^{-7} *$ & $15.4^{*}$ & $330^{*}$ \\
\hline FCAT-09 & $4608 *$ & $1.10 \times 10^{15}$ & $1.82 \times 10^{22 *}$ & $9.8 \times 10^{-7} *$ & $16.3^{*}$ & $550^{*}$ \\
\hline
\end{tabular}

*Target values represented, nominal values are currently being determined

\subsection{Preliminary PIE}

To date, the low dose $(<2 \mathrm{dpa})$ irradiation capsules have been removed from HFIR and transferred to hot cell facilities for preliminary PIE. Capsule opening was completed in cell with removal of each individual module at a time with their location recorded within the capsule. 
Specimens were then removed from individual modules, identified, and sorted. Specimen IDs were verified according to loading lists developed during the fabrication stage of the capsules. Accordingly, all specimens from the three low dose irradiation capsules corresponded exactly with the provided built sheets. Specimens removed from the $200^{\circ} \mathrm{C}$ and $330^{\circ} \mathrm{C}$ irradiation capsules showed no significant change in the surface quality. The samples removed from the $550^{\circ} \mathrm{C}$ irradiation capsule did show discoloration which could be indicative of surface oxidation during irradiation. The samples from this capsule typically showed a blue tint and hence oxidation is speculated to be a minimum. SiC thermometry samples were also in good condition although several samples fractured during opening or sample handling. This is expected and a major reason why a significant number of SiC thermometry specimens are loaded within each capsule.

All SiC thermometry samples were identified, cleaned, packaged and then shipped to the Low Activation Materials Development and Analysis (LAMDA) facility. LAMDA received samples had their sample numbers identified and then were re-cleaned per standard procedures. Table 3 summarizes the conditions of the SiC thermometry samples received in LAMDA from the low dose FCAT irradiation capsules. Selected samples in Table 3 were analyzed using dilatometric analysis to determine if the target irradiation temperatures have been met. One sample was taken from two radial opposing positions within each inner module of the irradiation capsule. The result is the determination of the radial and axial temperature gradients within the reactor during irradiation. For the low temperature irradiation capsules $\left(200^{\circ} \mathrm{C}\right.$ and $\left.330^{\circ} \mathrm{C}\right)$, dilatometric analysis was conducted up to a maximum temperature of $600^{\circ} \mathrm{C}$ at a constant ramp rate of $1^{\circ} \mathrm{C} / \mathrm{min}$ and a cooling rate of $2.5^{\circ} \mathrm{C} / \mathrm{min}$ using a Netzsch $402 \mathrm{CD}$ dilatometer. For the $550^{\circ} \mathrm{C}$ capsule, the same ramp rates were used but a maximum temperature of $900^{\circ} \mathrm{C}$ was used.

Table 4 provides the resulting dilatometric analysis of the selected $\mathrm{SiC}$ thermometry samples. As previously mentioned, $\mathrm{SiC}$ thermometry is expected to have higher reported temperature than the nominal specimen average irradiation temperatures. In general, the values reported in Table 4 are within the expected range of irradiation temperatures. For example, the $330^{\circ} \mathrm{C}$ and $550^{\circ} \mathrm{C}$ irradiations showed a $15^{\circ} \mathrm{C}$ variance between the expected and determined values for the $\mathrm{SiC}$ thermometry samples. The $200^{\circ} \mathrm{C}$ had a larger variance, $-47.5^{\circ} \mathrm{C}$, indicating the irradiation capsule was significantly lower than the design temperature. Additionally, minor axial variations in the radiation temperatures were also observed and this could be the result of the capsules being off-centered from the centerline of the reactor core. Unfortunately, capsule orientation to the centerline is not tracked during capsule insertion or removal and hence this assumption cannot be confirmed. 
Table 3: Condition of SiC thermometry samples originating from FCAT low dose irradiation capsules

\begin{tabular}{|c|c|c|c|}
\hline Capsule ID & Sample ID & Description & As-irradiated Condition \\
\hline \multirow{12}{*}{ FCAT-01 } & 1 & SiC thermometry & Unbroken \\
\hline & 2 & SiC thermometry & Unbroken \\
\hline & 3 & SiC thermometry & Unbroken \\
\hline & 4 & SiC thermometry & Unbroken \\
\hline & 5 & SiC thermometry & Unbroken \\
\hline & 6 & SiC thermometry & Unbroken \\
\hline & 7 & SiC thermometry & Unbroken \\
\hline & 8 & SiC thermometry & Unbroken \\
\hline & 9 & SiC thermometry & Not received \\
\hline & 10 & SiC thermometry & Unbroken \\
\hline & 11 & SiC thermometry & Broken \\
\hline & 12 & SiC thermometry & Not received \\
\hline \multirow{12}{*}{ FCAT-02 } & 13 & SiC thermometry & Unbroken \\
\hline & 14 & SiC thermometry & Unbroken \\
\hline & 15 & SiC thermometry & Unbroken \\
\hline & 16 & SiC thermometry & Unbroken \\
\hline & 17 & SiC thermometry & Unbroken \\
\hline & 18 & SiC thermometry & Unbroken \\
\hline & 19 & SiC thermometry & Unbroken \\
\hline & 20 & SiC thermometry & Unbroken \\
\hline & 21 & SiC thermometry & Unbroken \\
\hline & 22 & SiC thermometry & Unbroken \\
\hline & 23 & SiC thermometry & Unbroken \\
\hline & 24 & SiC thermometry & Unbroken \\
\hline \multirow{12}{*}{ FCAT-03 } & 25 & SiC thermometry & Unbroken \\
\hline & 26 & SiC thermometry & Unbroken \\
\hline & 27 & SiC thermometry & Unbroken \\
\hline & 28 & SiC thermometry & Unbroken \\
\hline & 29 & SiC thermometry & Unbroken \\
\hline & 30 & SiC thermometry & Unbroken \\
\hline & 31 & SiC thermometry & Unbroken \\
\hline & 32 & SiC thermometry & Unbroken \\
\hline & 33 & SiC thermometry & Unbroken \\
\hline & 34 & SiC thermometry & Unbroken \\
\hline & 35 & SiC thermometry & Unbroken \\
\hline & 36 & SiC thermometry & Unbroken \\
\hline
\end{tabular}


Table 4: Results of dilatometric analysis of SiC thermometry bars contained within irradiated capsules.

\begin{tabular}{|c|c|c|c|c|c|c|c|}
\hline \multicolumn{6}{|c|}{ Experimental Values } & \multicolumn{2}{|c|}{ Modeled Values } \\
\hline Capsule & Specimen & Minimum & Median & Maximum & $\begin{array}{l}\text { Average } \\
\text { Median }\end{array}$ & $\begin{array}{c}\text { Average } \\
\text { Median SiC } \\
\text { Specimen }\end{array}$ & $\begin{array}{c}\text { Average } \\
\text { Median SS- } \\
\text { J2 Specimen }\end{array}$ \\
\hline ID & ID & $\begin{array}{c}\text { Temp. } \\
\left({ }^{\circ} \mathrm{C}\right)\end{array}$ & $\begin{array}{c}\text { Temp. } \\
\left({ }^{\circ} \mathrm{C}\right)\end{array}$ & $\begin{array}{c}\text { Temp. } \\
\left({ }^{\circ} \mathrm{C}\right)\end{array}$ & Temp. $\left({ }^{\circ} \mathrm{C}\right)$ & Temp. $\left({ }^{\circ} \mathrm{C}\right)$ & Temp. $\left({ }^{\circ} \mathrm{C}\right)$ \\
\hline \multirow{6}{*}{$\begin{array}{c}\text { FCAT } \\
- \\
01\end{array}$} & 02 TOP & 178.5 & 169.2 & 229.8 & $1868+248$ & \multirow{6}{*}{242} & \multirow{6}{*}{219} \\
\hline & 04 TOP & 192.2 & 204.3 & 229.0 & $100.0 \pm 24.0$ & & \\
\hline & 06 MID & 186.8 & 143.4 & 235.0 & \multirow{2}{*}{$180.9 \pm 53.0$} & & \\
\hline & 08 MID & 198.1 & 218.4 & 239.6 & & & \\
\hline & $10 \mathrm{BOT}$ & 235.1 & 237.4 & 259.1 & 237.4 & & \\
\hline & Average & \multicolumn{4}{|c|}{$194.5 \pm 37.9$} & & \\
\hline \multirow{7}{*}{$\begin{array}{c}\text { FCAT } \\
- \\
02\end{array}$} & 14 TOP & 346.2 & 358.1 & 372.5 & & \multirow{7}{*}{347} & \multirow{7}{*}{333} \\
\hline & 16 TOP & 359.9 & 383 & 405.7 & $370.6 \pm 17.6$ & & \\
\hline & $18 \mathrm{MID}$ & 336.4 & 345.2 & 368.2 & $3640+1$ & & \\
\hline & $20 \mathrm{MID}$ & 394.1 & 384.6 & 402.1 & $364.9 \pm 21.9$ & & \\
\hline & $22 \mathrm{BOT}$ & 337.9 & 329.5 & 342.4 & \multirow{3}{*}{$355.5 \pm 36.7$} & & \\
\hline & 24 BOT & 369.9 & 381.4 & 403.1 & & & \\
\hline & Average & & 36 . & $6 \pm 23.1$ & & & \\
\hline \multirow{7}{*}{$\begin{array}{c}\text { FCAT } \\
- \\
\mathbf{0 3}\end{array}$} & 26 TOP & 450.1 & 524.3 & 571.5 & & \multirow{7}{*}{568} & \multirow{7}{*}{521} \\
\hline & 28 TOP & 635.0 & 589.1 & 601.1 & $556.7=$ & & \\
\hline & 30 MID & 517.7 & 551.0 & 574.5 & & & \\
\hline & 32 MID & 529.4 & 548.3 & 534.2 & $549.7 \pm$ & & \\
\hline & $34 \mathrm{BOT}$ & 488.4 & 573.1 & 597.6 & & & \\
\hline & $36 \mathrm{BOT}$ & 575.7 & 607.3 & 603.7 & $590.2 \pm$ & & \\
\hline & Average & \multicolumn{4}{|c|}{$559.4 \pm 28.1$} & & \\
\hline
\end{tabular}

A single tensile specimen of each alloy per irradiation capsule was tested in cell to determine the mechanical properties after irradiation. Tensile tests were completed using an Instron universal test machine with a crosshead speed of $0.0055 \mathrm{~mm} / \mathrm{s}$ resulting in a nominal strain rate of $\sim 10^{-3} \mathrm{~s}^{-}$ ${ }^{1}$. No contact or non-contact extensometery was completed at the time of the test. All tests were performed at room temperature in air with no post-irradiation surface preparation. Engineering stress-strain curves were calculated based on the digitally recorded load and measured crosssection of the gage region. All gage measurements were performed prior to irradiation and hence no correction was made for volumetric swelling in the specimens after neutron irradiation; although, swelling was assumed negligible based on the reports of Little and Stow [8]. All tests were performed on the SS-J2 tensile specimen geometry.

Resulting engineering stress-strain curves for the alloys of interest are provided in Figure 3. All wrought alloys performed in a similar manner. Irradiation at $200^{\circ} \mathrm{C}$ and $330^{\circ} \mathrm{C}$ below 2 dpa showed significant increases in yield strength and loss of ductility and reduction of load carrying capacity for the wrought alloy. Decreasing the irradiation temperature from $330^{\circ} \mathrm{C}$ to $200^{\circ} \mathrm{C}$ increased the magnitude of this response. This is qualitatively similar to the temperature dependence reported for $\mathrm{FeCr}$ alloys [9]. Irradiation to $550^{\circ} \mathrm{C}$ in the wrought alloys led to radiation-induced softening with a decrease in the yield strength and increases in the total elongation but limited change in the post-yield load carrying capacity. The results for the ODS $125 \mathrm{YF}$ specimens have been previously reported [10]. Compared to the wrought alloys, the ODS alloy showed significantly less radiation-induced hardening and embrittlement. This could be a 
sign of the positive influence of the nano-cluster oxide dispersions on the radiation tolerance of the ODS FeCrAl alloy class. Further PIE efforts, including advanced microstructural characterization, are needed to provide more insight on the radiation tolerance of the wrought and ODS FeCrAl alloy classes.

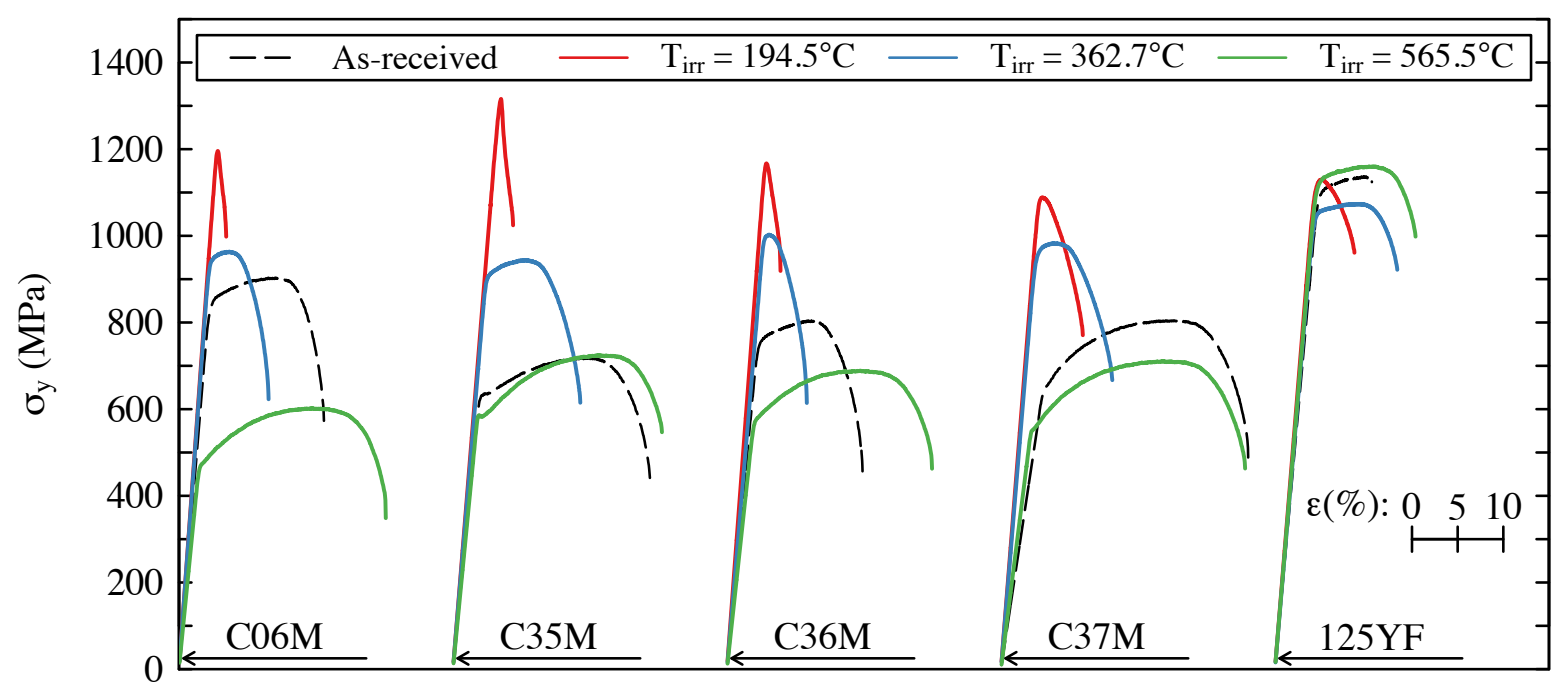

Figure 3: Plots showing engineering stress-strain curves before and after neutron irradiation to 1.8-1.9 dpa between $194.5^{\circ} \mathrm{C}$ and $565.5^{\circ} \mathrm{C}$ when tested at room temperature $\left(T_{\text {test }}=24^{\circ} \mathrm{C}\right)$.

\subsection{Planned PIE}

Immediate future PIE is planned to include the evaluation of the mechanical properties at irradiation temperature, room temperature microhardness, fractography, and microstructure on the low dose $(<2 \mathrm{dpa})$ irradiated specimens. High temperature mechanical testing will be performed on the same Instron tensile frame that the reported room temperature tests have been completed. Loading conditions will remain the same but tests will be performed under vacuum. Microhardness will be completed to provide a quick correlation between the change in yield strength and the change in microhardness. The developed correlation will be compared to those previously published for ferritic steels [11]. Broken tensile halves from the room temperature and high temperature tensile tests will be imaged using a remotely operated JEOL JSM-6010LA scanning electron microscope (SEM) for fractography investigations. Standard configurations will be used with reduction of area being measured from calibrated images. Microstructures will be primarily investigated using transmission and scanning transmission electron microscopy (S/TEM). Samples for microstructural investigation will be prepared using a focused ion beam (FIB) as FIB prepared specimens greatly reduces magnetic aberrations from the sample and reduces the overall radiological threat. Primary features of interest to study using S/TEM include dislocation loop and Cr-rich $\alpha^{\prime}$ precipitates morphologies.

After the completion of PIE on the low dose irradiation specimens it is expected that capsules FCAT-04, FCAT-05, and FCAT-06 will be ready for examination. Similar PIE is planned for the specimens contained within these capsules. Planned PIE, in conjunction with already completed 
PIE, will help to provide detailed insight on the role of irradiation dose, irradiation temperature, and alloy composition on the changes in mechanical properties and microstructure.

\section{FCAB IRRADIATION PROGRAM}

\subsection{Materials}

The FCAB irradiation program serves to complement the FCAT irradiation program. Hence, a subset of alloys from the FCAT irradiation program are used in the FCAB irradiation program. Of primary interest is the role of $\mathrm{Cr}$ content on the precipitation of the $\mathrm{Cr}$-rich $\alpha^{\prime}$ and resulting changes, if any, on the fracture properties of the FeCrAl alloys. Hence, the C06M and C36M alloys from Table 1 are used for the FCAB irradiation program. Sheet product for FCAB specimens were warm rolled to $80 \%$ reduction while tensile specimens were warm rolled to $90 \%$ reduction from the same base alloy heat. The result is some variation in the as-received microstructure is expected between the bend bar and previously reported tensile samples but the samples should be chemically identical.

\subsection{Irradiation capsule design}

The FCAB irradiation capsules are designed to solely hold four M4-PCCVN bend bar specimens and four $\mathrm{SiC}$ thermometry samples. The general design is shown in Figure 4. The design is optimized as a drop in capsule design for use in HFIR. Due to the larger number of tests needed to determine fracture properties, each capsule only contains two specimens (four notches, or four tests per specimen) per alloy type. Hence, only two alloys can be investigated in a single irradiation capsule. Similar to the FCAT designs, three separate capsule designs were developed to accommodate the three target temperatures described in the following section. Design changes were primarily focused on adjusting the radial gap between the sub-assembly and outter housing of the irradiation capsule. Helium fill gas was utilized for all three capsule designs.

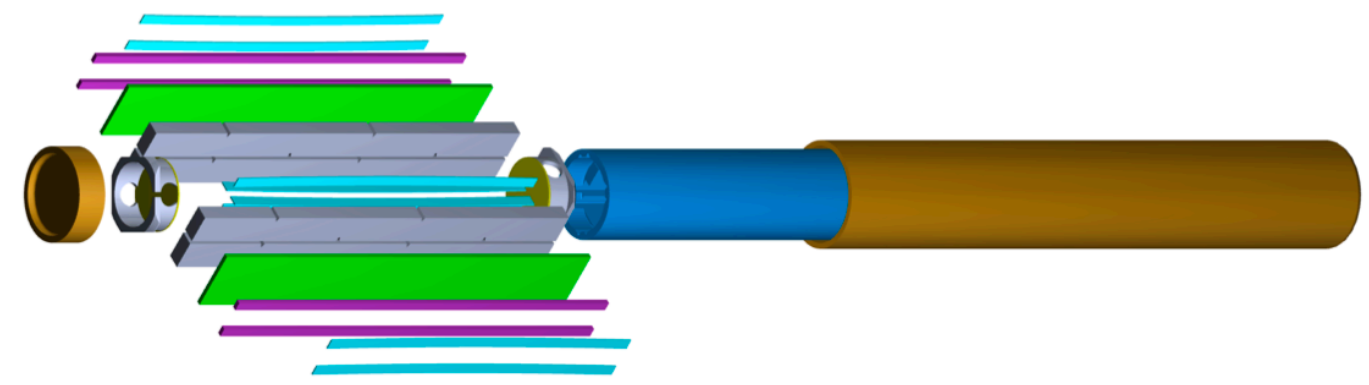

Figure 4: Finalized HFIR irradiation capsule design for the bend bar specimens.

A 3D FEA model was used to determine specimen contours during irradiation. Contrary to the FCAT design, the FCAB design places the SiC thermometry towards the outside of the irradiation capsule. The result is the specimen contours for the $\mathrm{SiC}$ thermometry are lower than that of the specimens as shown in Figure 5. Hence, reported SiC thermometry values during PIE will be lower than the specimen average irradiation temperature. Some axial variation in both the specimen and $\mathrm{SiC}$ samples are expected with fracture notches orientated near the axial center having higher irradiation temperatures than the outer notches. Even though care was taken to 
minimize this effect, due to the restrictions of the reactor position, it cannot be completely eliminated.

a)

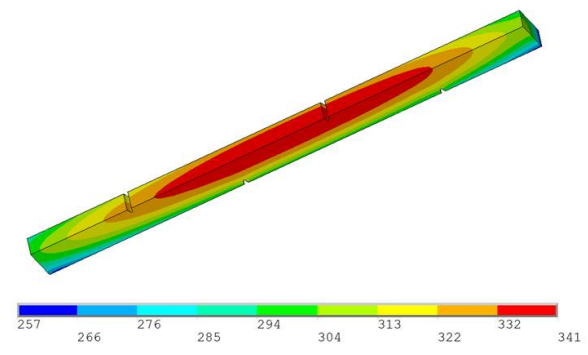

b)

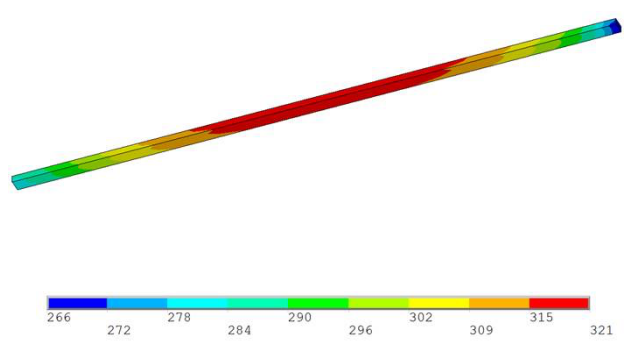

Figure 5: Predicted temperature contours for a $330^{\circ} \mathrm{C}$ irradiation in HFIR: a) specimen temperature contours and b) $\mathrm{SiC}$ thermometry contours. All temperatures in ${ }^{\circ} \mathrm{C}$.

\subsection{Irradiation test matrix}

FCAB irradiation dose and temperatures were selected to complement the FCAT irradiation program discussed earlier in this report while still providing cross-referencing abilities with the prior FCAY irradiation program. The low dose $(<2 \mathrm{dpa})$ irradiation capsules were not fielded for the FCAB irradiation program. This decision is based on prior knowledge that the alloys of interest might not hit saturation in the fracture toughness shift and hence would not provide the needed data to meet the objectives of the irradiation campaign. Table 5 provides the consolidated FCAB irradiation test matrix while Figure 6 provides the sample loading scheme for each irradiation capsule. Note, specimens starting with "BZM" are C06M M4-PCCVN bend bar specimens while those starting with "BM6" are C36M M4-PCCVN bend bar specimens; samples with purely numeric characters are the passive $\mathrm{SiC}$ thermometry samples. Each individual bend bar specimen has additional marking of " $A$ " through " $D$ " for each individual notch to keep traceability.

Table 5: Summary of FCAB capsule irradiation conditions.

\begin{tabular}{|c|c|c|c|c|c|c|}
\hline Capsule ID & $\begin{array}{l}\text { Exposure } \\
\text { Time } \\
\text { (hrs) }\end{array}$ & $\begin{array}{c}\begin{array}{c}\text { Neutron Flux } \\
\left(\mathrm{n} / \mathrm{cm}^{2} \mathrm{~s}\right) \\
\mathrm{E}>0.1 \mathrm{MeV}\end{array} \\
\end{array}$ & $\begin{array}{c}\text { Neutron Fluence } \\
\left(\mathbf{n} / \mathrm{cm}^{2}\right) \\
\mathbf{E}>\mathbf{0 . 1} \mathrm{MeV}\end{array}$ & $\begin{array}{c}\text { Dose Rate } \\
\text { (dpa/s) }\end{array}$ & $\begin{array}{l}\text { Dose } \\
\text { (dpa) }\end{array}$ & $\begin{array}{c}\text { Irradiation } \\
\text { Temperature } \\
\left({ }^{\circ} \mathrm{C}\right)\end{array}$ \\
\hline FCAB-01 & $2304 *$ & $1.04 \times 10^{15}$ & $8.63 \times 10^{21} *$ & $9.3 \times 10^{-7} *$ & $7.7 *$ & $200 *$ \\
\hline FCAB-02 & $2304 *$ & $1.04 \times 10^{15}$ & $8.63 \times 10^{21} *$ & $9.3 \times 10^{-7} *$ & $7.7 *$ & $330 *$ \\
\hline FCAB-03 & $2304 *$ & $1.08 \times 10^{15}$ & $8.96 \times 10^{21} *$ & $9.8 \times 10^{-7} *$ & $8.0 *$ & $550 *$ \\
\hline FCAB-04 & $4608^{*}$ & $1.08 \times 10^{15}$ & $1.79 \times 10^{22} *$ & $9.8 \times 10^{-7} *$ & $16.0^{*}$ & $200 *$ \\
\hline FCAB-05 & $4608^{*}$ & $1.08 \times 10^{15}$ & $1.79 \times 10^{22} *$ & $9.3 \times 10^{-7} *$ & $16.0^{*}$ & $330 *$ \\
\hline FCAB-06 & $4608 *$ & $1.10 \times 10^{15}$ & $1.82 \times 10^{22} *$ & $9.8 \times 10^{-7} *$ & $16.3^{*}$ & $550 *$ \\
\hline
\end{tabular}

*Target values represented, nominal values are currently being determined 

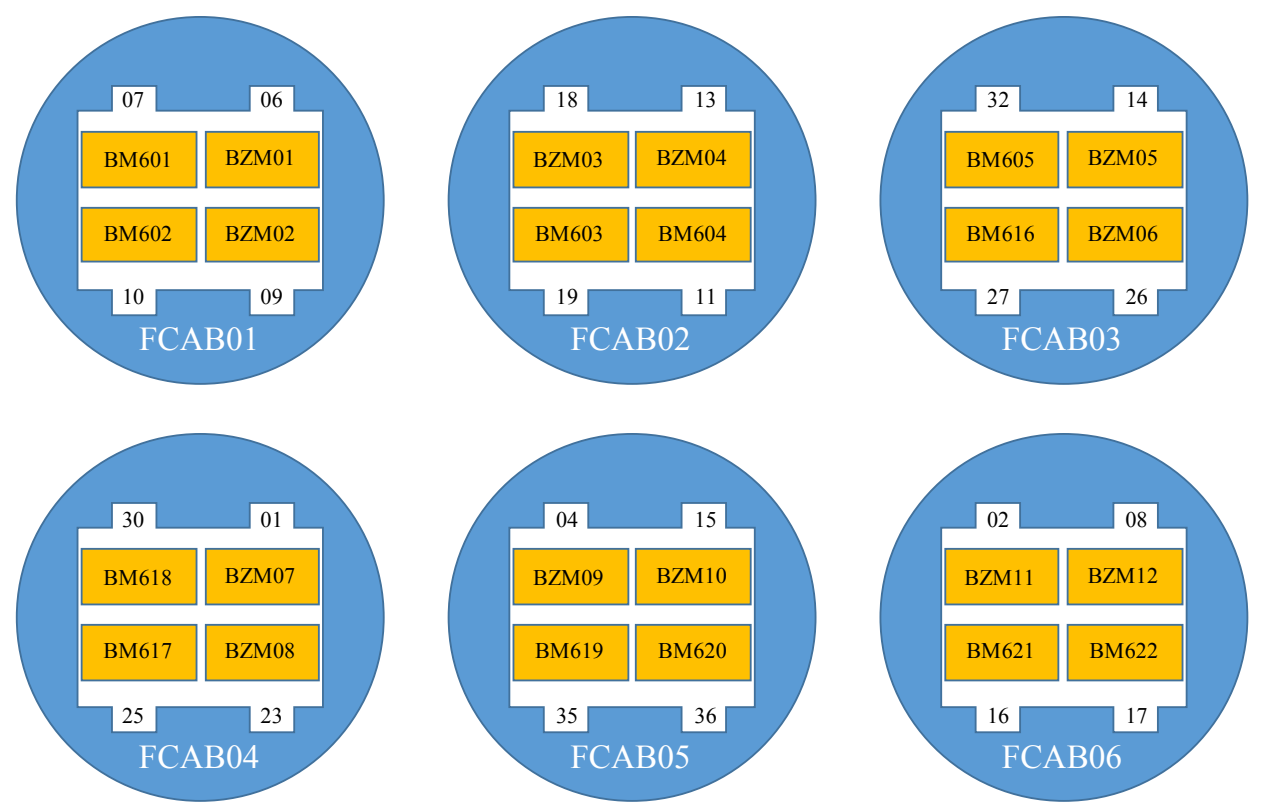

Figure 6: Sample loading scheme for each FCAB irradiation capsule. ID numbers in the yellow rectangles represent ID numbers for individual 4 notch bend bar specimens. ID numbers in white area cut-outs represent individual passive $\mathrm{SiC}$ thermometry.

\subsection{Planned PIE}

Primary planned PIE for the FCAB irradiation program is fracture toughness studies in general accordance with the ASTM E1921 standard. Test temperatures will be coordinated based on the available tensile data from the FCAT irradiation program and from microhardness measurements on the bend bars prior to the fracture toughness tests. The primary goal will be to measure the reference fracture toughness transition temperature, $T_{0}$. Hence, fracture via cleavage is expected as long as careful consideration of the test temperature is taken. An effort will be made to determine if any specimens develop a J-R curve from which the $\mathrm{J}_{\text {intergal }}$ at the onset of stable crack growth, $\mathrm{J}_{\mathrm{Q}}$, can be determined. Additional PIE could include SEM based fractography. FCAB-01, FCAB-02, and FCAB-03 will be ready for preliminary PIE after irradiation in Cycle 469 in the HFIR. Cycle 469 is scheduled to be completed on December 12, 2016. All other FCAB irradiation capsules are scheduled for irradiation completion by late July 2017.

\section{REFERENCES}

[1] K.G. Field, X. Hu, K.C. Littrell, Y. Yamamoto, L.L. Snead, Radiation tolerance of neutronirradiated model Fe-Cr-Al alloys, J. Nucl. Mater. 465 (2015) 746-755. doi:10.1016/j.jnucmat.2015.06.023.

[2] M.A. Sokolov, H. Tanigawa, G.R. Odette, K. Shiba, R.L. Klueh, Fracture toughness and Charpy impact properties of several RAFMS before and after irradiation in HFIR, J. Nucl. Mater. 367-370 (2007) 68-73. doi:10.1016/j.jnucmat.2007.03.165.

[3] K.G. Field, R.H. Howard, Y. Yamamoto, Experimental Plan and Irradiation Target Design for FeCrAl Embrittlement Screening Tests Conducted Using the High Flux Isotope Reactor, ORNL/TM-2015/311. (2015).

[4] K.G. Field, M.N. Gussev, R. Howard, First Annual Progress Report on Radiation Tolerance of 
Controlled Fusion Welds in High Temperature Oxidation Resistant FeCrAl Alloys, ORNL/TM2015/770. (2015).

[5] K.G. Field, S.A. Briggs, P.D. Edmondson, J.C. Haley, R.H. Howard, X. Hu, et al., Database on Performance of Neutron Irradiated FeCrAl Alloys, ORNL/TM-2016/335. (2016).

[6] Y. Yamamoto, K.A. Terrani, Optimized Gen-II FeCrAl cladding production in large quantity for campaign testing, ORNL/TM-2016/227. (2016).

[7] Y. Yamamoto, B.A. Pint, K.A. Terrani, K.G. Field, Y. Yang, L.L. Snead, Development and property evaluation of nuclear grade wrought FeCrAl fuel cladding for light water reactors, J. Nucl. Mater. 467 (2015) 703-716. doi:10.1016/j.jnucmat.2015.10.019.

[8] E.A. Little, D.A. Stow, Void-swelling in irons and ferritic steels, J. Nucl. Mater. 87 (1979) 25-39.

[9] O. Anderoglu, T.S. Byun, M. Toloczko, S.A. Maloy, Mechanical Performance of Ferritic Martensitic Steels for High Dose Applications in Advanced Nuclear Reactors, Metall. Mater. Trans. A. 44 (2013) 70-83. doi:10.1007/s11661-012-1565-y.

[10] K.G. Field, R.H. Howard, Status of FeCrAl ODS Irradiations in the High Flux Isotope Reactor, ORNL/TM-2016/394. (2016).

[11] J.T. Busby, M.C. Hash, G.S. Was, The relationship between hardness and yield stress in irradiated austenitic and ferritic steels, J. Nucl. Mater. 336 (2005) 267-278. doi:10.1016/j.jnucmat.2004.09.024. 